\title{
Synthesis and Antiviral Evaluation of 7-O-Arylmethylquercetin Deri- vatives against SARS-associated Coronavirus (SCV) and Hepatitis C Virus (HCV)
}

\author{
Hye Ri Park ${ }^{1, *}$, Hyunjun Yoon ${ }^{1, *}$, Mi Kyoung Kim¹, Sung Dae Lee ${ }^{2}$, and Youhoon Chong ${ }^{1}$ \\ ${ }^{1}$ Department of Bioscience and Biotechnology, Bio/Molecular Informatics Center, Konkuk University, Seoul 143-701, \\ Korea and ${ }^{2}$ Swine Science Division, National Institute of Animal Science, RDA, Cheonan 330-801, Korea
}

(Received June 18, 2011/Revised July 29, 2011/Accepted August 9, 2011)

\begin{abstract}
Aryl diketoacid (ADK) is well known for antiviral activity which can be enhanced by introduction of an aromatic arylmethyl substituent. A natural flavonoid quercetin has a 3,5-dihydroxychromone pharmacophore which is in bioisosteric relationship with the 1,3-diketoacid moiety of the ADK. Thus, it was of our interest to test the antiviral activity of the quercetin derivatives with an arylmethyl group attached. In this study, we prepared a series of the 7-O-arylmethylquercetin derivatives with various aromatic substituents and evaluated their antiviral activity against the SARS-associated coronavirus (SARS-CoV, SCV) as well as hepatitis C virus (HCV). Single difference in the aromatic substituent fine-tuned the biological activity of the 7-O-arylmethylquercetin derivatives to result in two different classes of derivatives selectively active against SCV and HCV.
\end{abstract}

Key words: Quercetin, Arylmethyl, Hepatitis C, Severe acute respiratory syndrome (SARS)

\section{Selected by Editors}

\section{INTRODUCTION}

Quercetin (1, Fig. 1) is widely distributed in the plant kingdom and is the most abundant of the flavonoid family. It is often a major component of the medicinal activity of the plant, and has been shown in experimental studies to have numerous effects on the body. Quercetin appears to have many beneficial effects on human health, including cardiovascular protection, anticancer activity, antiulcer effects, antiallergy activity, cataract prevention, and anti-inflammatory effects. In addition, quercetin exerts antiviral activity against reverse transcriptase of HIV (Harada et al., 1999) and other retroviruses, and was shown to reduce the infectivity and cellular replication of herpes simplex virus

*These authors contributed equally to this work.

Correspondence to: Youhoon Chong, Department of Bioscience \& Biotechnology, Konkuk University, Seoul 143-701, Korea Tel:82-2-2049-6100, Fax: 82-2-454-8217

E-mail: chongy@konkuk.ac.kr type 1 (Amoros et al., 1992), polio-virus type 1 (Vrijsen et al., 1988), parainfluenza virus type 3, and respiratory syncytial virus (RSV) (Kaul et al., 1985). Recently, we have also shown inhibition of the helicase activity of the SARS-associated coronavirus (SARS-CoV, SCV) by quercetin $\left(\mathrm{IC}_{50}=8.1 \mu \mathrm{M}\right)$ (Lee et al., 2009a). More interestingly, introduction of arylmethyl substituent such as $4-\mathrm{ClPhCH}_{2}, 3-\mathrm{ClPhCH}_{2}$, and $3-\mathrm{CNPhCH}_{2}$ at the 7-OH position of quercetin provided the resulting quercetin derivatives (2, Fig. 1) with significantly increased inhibitory activity against the SCV helicase $\left(\mathrm{IC}_{50}=4.1,5.2,2.7 \mu \mathrm{M}\right.$, respectively).

At this point, it is worth to note that the core 3,5dihydroxychromone moiety of the quercetin (bold lines in 1, Fig. 1) is in match with the 1,3-diketoacid (bold lines in 3, Fig. 1), the key pharmacophoric element of the antiviral aryl diketoacid (ADK) (3, Fig. 1), in atom-by-atom fashion. Also, in line with the substituted quercetins, the arylmethyloxy substituent (dotted box in 3, Fig. 1) increased the antiviral activity of the $\mathrm{ADKs}$ and the substituted ADKs showed potent inhibition of the RNA-dependent RNA polymerase (RdRp) of hepatitis C virus (HCV) (Kim et al., 2008) as well as the SCV NTPase/helicase (Lee et al., 2009b). 


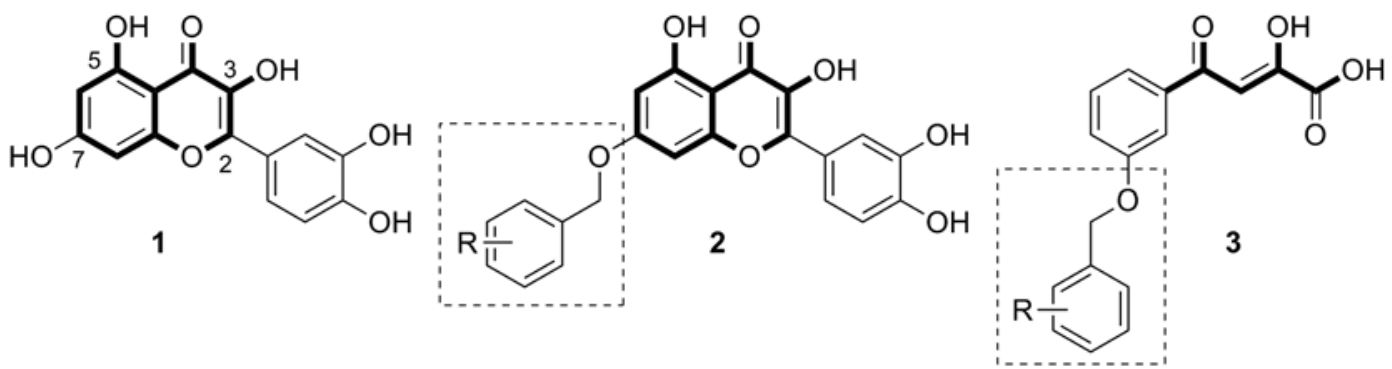

Fig. 1. Structures of quercetin (1), 7-O-arylmethylquercetin (2), and aryl diketoacid (3)

Prompted by these intriguing results which support the bioisosteric relationship of the 3,5-dihydroxychromone with 1,3-diketoacid as well as the critical role of the arylmethyl substituents in antiviral activity, we initiated structure-activity relationship study of a series of 7-O-arylmethylquercetin derivatives (2, Fig. 1) with various aromatic substituents ( $R$ in 2 , Fig. 1). Also, the antiviral activity of the ADKs against both SCV and HCV was of another interest and thus, antiviral screening program was extended to include anti-HCV activity. Herein, we report preparation of a series of the 7-O-arylmethylquercetin derivatives (2, Fig. 1) with various aromatic substituents and evaluation of their anti-SCV as well as anti-HCV activity.

\section{MATERIALS AND METHODS}

\section{Chemicals}

All chemicals were purchased from Sigma-Aldrich. Dulbecco's Modified Eagle Media (DMEM), penicillin, streptomycin and fetal bovine serum (FBS) were purchased from Invitrogen. TLC was performed on Silica Gel 60 F254 purchased from Merck. Column chromatography was performed using either Slica Gel 60 (220-440 mesh). Melting points were measured with an electrothermal melting-point apparatus (SMP10, Barloworld Scientific) in open capillary tubes and are uncorrected. Nuclear magnetic resonance spectra were recorded on a bruker 400 AMX spectrometer at $400 \mathrm{MHz}$ for ${ }^{1} \mathrm{H}-\mathrm{NMR}$ and at $100 \mathrm{MHz}$ for ${ }^{13} \mathrm{C}-\mathrm{NMR}$ with tetramethylsilane as the internal standard. Chemical shift are reported as s (singlet), d, (doublet), $\mathrm{t}$ (triplet), q (quartet), $\mathrm{m}$ (multiplet), or br s (broad singlet). Coupling constants are reported in hertz $(\mathrm{Hz})$. The chemical shifts are reported as parts per million ( $\delta)$ relative to the solvent peak. Mass spectrometric data (MS) were obtained by MALDI-TOF-TOF mass spectrometer (Ultraflex III, Bruker Daltonik).

2-(3,4-Diacetoxyphenyl)-4-oxo-4H-chromene-3,5, 7-triyl triacetate (4)

$\mathrm{Ac}_{2} \mathrm{O}(12.5 \mathrm{~mL}, 135 \mathrm{mmol})$ was added to a stirred solu- tion of quercetin ( $5 \mathrm{~g}, 16.5 \mathrm{mmol})$ in anhydrous pyridine $(40 \mathrm{~mL})$, and the reaction mixture was stirred at $80^{\circ} \mathrm{C}$ for $4 \mathrm{~h}$. After cooling to room temperature, solvent was removed under reduced pressure. The crude product was purified by column chromatography on silica gel (Hexane-Acetone- $\mathrm{CH}_{2} \mathrm{Cl}_{2}=4: 1: 1$ ) to afford the desired quercetin peracetate 4 ( $4.5 \mathrm{~g}, 54 \%$ yield) as off-white powder: ${ }^{1} \mathrm{H}-\mathrm{NMR}\left(400 \mathrm{MHz}, \mathrm{CDCl}_{3}\right) \delta 7.72(\mathrm{dd}, J=$ $8.6,2.0 \mathrm{~Hz}, 1 \mathrm{H}), 7.70(\mathrm{~d}, J=1.9 \mathrm{~Hz}, 1 \mathrm{H}), 7.35(\mathrm{~d}, J=8.6$ $\mathrm{Hz}, 1 \mathrm{H}), 7.33(\mathrm{~d}, J=2.2 \mathrm{~Hz}, 1 \mathrm{H}), 6.88(\mathrm{~d}, J=2.2 \mathrm{~Hz}$, $1 \mathrm{H}), 2.43(\mathrm{~s}, 3 \mathrm{H}), 2.34(\mathrm{~s}, 12 \mathrm{H})$.

\section{4-(3,5-Diacetoxy-7-hydroxy-4-oxo-4H-chromen-} 2-yl)-1,2-phenylene diacetate (5)

The quercetin peracetate obtained above (4) (3 g, 5.9 $\mathrm{mmol})$ and imidazole $(80 \mathrm{mg}, 1.2 \mathrm{mmol})$ were dissolved in NMP (30 mL). Thiophenol $(0.5 \mathrm{~mL}, 4.7 \mathrm{mmol})$ was slowly added to the stirred mixture at $0^{\circ} \mathrm{C}$ and then the reaction mixture was stirred at room temperature. After $2 \mathrm{~h}$, the mixture was diluted with EtOAc and washed with $2 \mathrm{~N} \mathrm{HCl}$. The organic layer was dried over $\mathrm{MgSO}_{4}$, filtered and evaporated. The crude product thus obtained was purified by column chromatography on silica gel (Hexane-Acetone- $\mathrm{CH}_{2} \mathrm{Cl}_{2}=2: 1: 1$ ) to afford $\mathbf{5}$ ( $2 \mathrm{~g}, 74 \%$ yield) as white powder: ${ }^{1} \mathrm{H}-\mathrm{NMR}(400 \mathrm{MHz}$, DMSO- $\left._{6}\right) \delta 11.33(\mathrm{~s}, 1 \mathrm{H}), 7.83-7.80(\mathrm{~m}, 2 \mathrm{H}), 7.51(\mathrm{~d}, J$ $=8.5 \mathrm{~Hz}, 1 \mathrm{H}), 6.94(\mathrm{~s}, 1 \mathrm{H}), 6.65(\mathrm{~s}, 1 \mathrm{H}), 2.33(\mathrm{~s}, 6 \mathrm{H})$, $2.30(\mathrm{~s}, 6 \mathrm{H})$.

General procedure for preparation of the 7-Oarylmethylquercetins (2)

Substituted benzylbromide (1.2 eq.) was added to a stirred solution of 5 (1.0 eq.) and $\mathrm{K}_{2} \mathrm{CO}_{3}$ (1.2 eq.) in acetone, and the reaction mixture was stirred at room temperature. The reaction was monitored by TLC. After starting material was consumed, the inorganic residues were removed by filtration. The filtrate was concentrated under reduced pressure to give a pale yellow powder, which was used for the next step without further purification. The crude product was dissolved in $\mathrm{MeOH}$ saturated with ammonia, and the reaction mixture was stirred at $0^{\circ} \mathrm{C}$ for $1 \mathrm{~h}$. After con- 
centration under reduced pressure, the residue was purified by column chromatography on silica gel $\left(\mathrm{CH}_{2} \mathrm{Cl}_{2}-\mathrm{MeOH}=20: 1\right)$ to give the desired product (2).

7-(Benzyloxy)-2-(3,4-dihydroxyphenyl)-3,5-dihydroxy-4H-chromen-4-one (2a)

The desired product 2a was obtained as a yellow powder in $43 \%$ yield: m.p. $260-263^{\circ} \mathrm{C}$ (dec); ${ }^{1} \mathrm{H}-\mathrm{NMR}$ $\left(500 \mathrm{MHz}, \mathrm{CD}_{3} \mathrm{COCD}_{3}\right) \delta 7.86(\mathrm{~s}, 1 \mathrm{H}), 7.71(\mathrm{~d}, J=8.0$ $\mathrm{Hz}, 1 \mathrm{H}), 7.52(\mathrm{~d}, J=7.5 \mathrm{~Hz}, 2 \mathrm{H}), 7.42(\mathrm{t}, J=7.5 \mathrm{~Hz}$, $2 \mathrm{H}), 7.39-7.34(\mathrm{~m}, 1 \mathrm{H}), 7.00(\mathrm{~d}, J=8.5 \mathrm{~Hz}, 1 \mathrm{H}), 6.77$ $(\mathrm{s}, 1 \mathrm{H}), 6.40(\mathrm{~s}, 1 \mathrm{H}), 5.26(\mathrm{~s}, 2 \mathrm{H}) ;{ }^{13} \mathrm{C}-\mathrm{NMR}(100 \mathrm{MHz}$, DMSO- $\left.d_{6}\right) \delta 176.3,164.2,160.8,156.3,148.2,147.7$, $145.5,143.9,136.6,136.4,129.0,128.3,122.2$, 116.0, 115.9, 115.6, 104.5, 98.4, 98.3, 93.2, 93.0, 70.3; LC/MS (ESI) $\mathrm{m} / z$ Found: $393.40(\mathrm{M}+\mathrm{H})^{+}$; Calcd for $\mathrm{C}_{22} \mathrm{H}_{17} \mathrm{O}_{7}$ : 393.10 .

2-(3,4-Dihydroxyphenyl)-7-(2-fluorobenzyloxy)-3, 5-dihydroxy-4H-chromen-4-one (2b)

The desired product $\mathbf{2 b}$ was obtained as a yellow powder in $29 \%$ yield: m.p. $255-257^{\circ} \mathrm{C}$ (dec); ${ }^{1} \mathrm{H}-\mathrm{NMR}$ $\left(400 \mathrm{MHz}, \mathrm{CD}_{3} \mathrm{COCD}_{3}\right) \delta 7.87(\mathrm{~s}, 1 \mathrm{H}), 7.73(\mathrm{~d}, J=8.3$ $\mathrm{Hz}, 1 \mathrm{H}), 7.63(\mathrm{t}, J=7.1 \mathrm{~Hz}, 1 \mathrm{H}), 7.46(\mathrm{~d}, J=7.3 \mathrm{~Hz}$, $1 \mathrm{H}), 7.29-7.20(\mathrm{~m}, 2 \mathrm{H}), 7.00(\mathrm{~d}, J=8.4 \mathrm{~Hz}, 1 \mathrm{H}), 6.83$ $(\mathrm{s}, 1 \mathrm{H}), 6.42(\mathrm{~d}, J=1.3 \mathrm{~Hz}, 1 \mathrm{H}), 5.33(\mathrm{~s}, 2 \mathrm{H}) ;{ }^{13} \mathrm{C}-\mathrm{NMR}$ $\left(100 \mathrm{MHz}\right.$, DMSO- $\left.d_{6}\right) \delta 176.3,164.0,162.1,160.8,159.6$, $156.4,148.3,147.8,145.5,143.9,136.5,131.4,124.9$, 123.5, 123.3, 122.2, 120.2, 116.0, 104.6, 98.3, 93.0, 64.7; LC/MS (ESI) $m / z$ Found: $411.30(\mathrm{M}+\mathrm{H})^{+}$; Calcd for $\mathrm{C}_{22} \mathrm{H}_{16} \mathrm{FO}_{7}$ : 411.09 .

7-(2-Chlorobenzyloxy)-2-(3,4-dihydroxyphenyl)-3, 5-dihydroxy-4H-chromen-4-one (2c)

The desired product 2c was obtained as a yellow powder in $22 \%$ yield: m.p. $252-255^{\circ} \mathrm{C}$ (dec); ${ }^{1} \mathrm{H}-\mathrm{NMR}$ $\left(500 \mathrm{MHz}, \mathrm{CD}_{3} \mathrm{COCD}_{3}\right) \delta 7.86(\mathrm{~s}, 1 \mathrm{H}), 7.73(\mathrm{~d}, J=8.5$ $\mathrm{Hz}, 1 \mathrm{H}), 7.67-7.65(\mathrm{~m}, 1 \mathrm{H}), 7.52-7.5(\mathrm{~m}, 1 \mathrm{H}), 7.42-7.40$ $(\mathrm{m}, 2 \mathrm{H}), 7.00(\mathrm{~d}, J=8.5 \mathrm{~Hz}, 1 \mathrm{H}), 6.82(\mathrm{~s}, 1 \mathrm{H}), 6.43(\mathrm{~s}$, $1 \mathrm{H}), 5.34(\mathrm{~s}, 2 \mathrm{H}) ;{ }^{13} \mathrm{C}-\mathrm{NMR}\left(100 \mathrm{MHz}, \mathrm{DMSO}-d_{6}\right) \delta$ $176.3,164.0,160.8,156.4,148.3,147.8,145.5,136.5$, $133.9,133.3,131.0,130.8,130.1,129.7,128.0,127.7$, 122.2, 120.6, 116.0, 104.7, 93.0, 68.0; LC/MS (ESI) $\mathrm{m} /$ $z$ Found: $427.40(\mathrm{M}+\mathrm{H})^{+}$; Calcd for $\mathrm{C}_{22} \mathrm{H}_{16} \mathrm{ClO}_{7}$ : 427.06 .

7-(2-Bromobenzyloxy)-2-(3,4-dihydroxyphenyl)-3, 5-dihydroxy-4H-chromen-4-one (2d)

The desired product 2d was obtained as a yellow powder in $20 \%$ yield: m.p. $248-250^{\circ} \mathrm{C}$ (dec); ${ }^{1} \mathrm{H}-\mathrm{NMR}$ $\left(400 \mathrm{MHz}, \mathrm{CD}_{3} \mathrm{COCD}_{3}\right) \delta 7.86(\mathrm{~s}, 1 \mathrm{H}), 7.74-7.64(\mathrm{~m}$, $3 \mathrm{H}), 7.45(\mathrm{t}, J=7.5 \mathrm{~Hz}, 1 \mathrm{H}), 7.33(\mathrm{t}, J=7.5 \mathrm{~Hz}, 1 \mathrm{H})$, $7.00(\mathrm{~d}, J=8.5 \mathrm{~Hz}, 1 \mathrm{H}), 6.79(\mathrm{~d}, J=1.4 \mathrm{~Hz}, 1 \mathrm{H}), 6.42$ $(\mathrm{d}, J=1.6 \mathrm{~Hz}, 1 \mathrm{H}), 5.29(\mathrm{~s}, 2 \mathrm{H}) ;{ }^{13} \mathrm{C}-\mathrm{NMR}(100 \mathrm{MHz}$,
DMSO- $\left.d_{6}\right) \delta 176.3,164.0,160.8,156.4,148.3,147.8$, 145.5, 136.5, 135.4, 133.1, 131.0, 130.8, 128.4, 123.5, $122.2,120.4,115.9,115.6,104.7,98.3,93.0,70.2$; LC/ MS (ESI) $m / z$ Found: $471.80(\mathrm{M}+\mathrm{H})^{+}$; Calcd for $\mathrm{C}_{22} \mathrm{H}_{16} \mathrm{BrO}_{7}$ : 471.01 .

2-(3,4-Dihydroxyphenyl)-3,5-dihydroxy-7-(2-iodobenzyloxy)-4H-chromen-4-one (2e)

The desired product $\mathbf{2 e}$ was obtained as a yellow powder in $18 \%$ yield: m.p. $252-255^{\circ} \mathrm{C}$ (dec); ${ }^{1} \mathrm{H}-\mathrm{NMR}$ $\left(400 \mathrm{MHz}, \mathrm{CD}_{3} \mathrm{COCD}_{3}\right) \delta 7.97(\mathrm{dd}, J=7.9,0.7 \mathrm{~Hz}, 1 \mathrm{H})$, $7.86(\mathrm{~d}, J=1.8 \mathrm{~Hz}, 1 \mathrm{H}), 7.73(\mathrm{dd}, J=8.5,1.3 \mathrm{~Hz}, 1 \mathrm{H})$, 7.62 (dd, $J=7.6,1.3 \mathrm{~Hz}, 1 \mathrm{H}), 7.49$ (t, $J=7.0 \mathrm{~Hz}, 1 \mathrm{H})$, $7.16(\mathrm{t}, J=7.6 \mathrm{~Hz}, 1 \mathrm{H}), 7.01(\mathrm{~d}, J=8.6 \mathrm{~Hz}, 1 \mathrm{H}), 6.81$ $(\mathrm{d}, J=2.1 \mathrm{~Hz}, 1 \mathrm{H}), 6.43(\mathrm{~d}, J=2.1 \mathrm{~Hz}, 1 \mathrm{H}), 5.24(\mathrm{~s}$, $2 \mathrm{H}) ;{ }^{13} \mathrm{C}-\mathrm{NMR}\left(125 \mathrm{MHz}, \mathrm{DMSO}-d_{6}\right) \delta 176.4,164.2$, $160.9,156.5,148.3,147.9,145.6,139.8,138.6,136.6$, 131.0, 130.7, 129.0, 122.3, 120.5, 116.1, 115.8, 104.8, 100.1, 98.4, 93.2, 74.5; LC/MS (ESI) $\mathrm{m} / z$ Found: $519.30(\mathrm{M}+\mathrm{H})^{+}$; Calcd for $\mathrm{C}_{22} \mathrm{H}_{16} \mathrm{IO}_{7}: 518.99$.

2-((2-(3,4-Dihydroxyphenyl)-3,5-dihydroxy-4-oxo4H-chromen-7-yloxy)methyl)benzo-nitrile (2f)

The desired product $\mathbf{2 f}$ was obtained as a yellow powder in $28 \%$ yield: m.p. $244-246^{\circ} \mathrm{C}$ (dec); ${ }^{1} \mathrm{H}-\mathrm{NMR}$ (500 $\left.\mathrm{MHz}, \mathrm{CD}_{3} \mathrm{COCD}_{3}\right) \delta 7.88(\mathrm{t}, J=8.0 \mathrm{~Hz}, 2 \mathrm{H}), 7.83-7.77$ $(\mathrm{m}, 3 \mathrm{H}), 7.73(\mathrm{~d}, J=8.5 \mathrm{~Hz}, 1 \mathrm{H}), 7.62(\mathrm{t}, J=7.3 \mathrm{~Hz}$, $1 \mathrm{H}), 7.00(\mathrm{~d}, J=8.0 \mathrm{~Hz}, 1 \mathrm{H}), 6.88(\mathrm{~s}, 1 \mathrm{H}), 6.47(\mathrm{~s}, 1 \mathrm{H})$, $5.46(\mathrm{~s}, 2 \mathrm{H}) ;{ }^{13} \mathrm{C}-\mathrm{NMR}\left(100 \mathrm{MHz}, \mathrm{DMSO}-d_{6}\right) \delta 176.3$, $163.8,160.8,156.3,148.3,147.8,145.5,139.5,136.5$, $134.0,129.8,122.2,120.4,117.5,116.0,115.9,111.8$, 104.8, 98.3, 98.2, 93.2, 93.1, 68.6; LC/MS (ESI) $\mathrm{m} / z$ Found: $418.30(\mathrm{M}+\mathrm{H})^{+}$; Calcd for $\mathrm{C}_{23} \mathrm{H}_{16} \mathrm{NO}_{7}$ : 418.09 .

2-(3,4-Dihydroxyphenyl)-3,5-dihydroxy-7-(2-nitrobenzyloxy)-4H-chromen-4-one (2g)

The desired product $\mathbf{2} \mathbf{g}$ was obtained as a yellow powder in $22 \%$ yield: m.p. $240-243^{\circ} \mathrm{C}$ (dec); ${ }^{1} \mathrm{H}-\mathrm{NMR}$ $\left(400 \mathrm{MHz}, \mathrm{CD}_{3} \mathrm{COCD}_{3}\right) \delta 8.20(\mathrm{~d}, J=8.1 \mathrm{~Hz}, 1 \mathrm{H})$, $7.91-7.80(\mathrm{~m}, 3 \mathrm{H}), 7.71(\mathrm{~d}, J=8.3 \mathrm{~Hz}, 1 \mathrm{H}), 7.66(\mathrm{t}, J=$ $7.6 \mathrm{~Hz}, 1 \mathrm{H}), 6.99(\mathrm{~d}, J=8.39 \mathrm{~Hz}, 1 \mathrm{H}), 6.82(\mathrm{~s}, 1 \mathrm{H})$, $6.45(\mathrm{~s}, 1 \mathrm{H}), 5.67(\mathrm{~s}, 2 \mathrm{H}) ;{ }^{13} \mathrm{C}-\mathrm{NMR}(100 \mathrm{MHz}, \mathrm{DMSO}-$ $\left.d_{6}\right) \delta 176.3,163.7,160.9,156.3,148.3,147.8,147.7$, $145.5,136.5,134.6,132.1,129.7,129.5,125.6,125.1$, 122.2, 115.9, 115.6, 104.8, 98.4, 93.2, 67.4; LC/MS (ESI) $m / z$ Found: $438.40(\mathrm{M}+\mathrm{H})^{+}$; Calcd for $\mathrm{C}_{22} \mathrm{H}_{16} \mathrm{NO}_{9}$ : 438.08 .

2-(3,4-Dihydroxyphenyl)-3,5-dihydroxy-7-(2-methylbenzyloxy)-4H-chromen-4-one (2h)

The desired product $\mathbf{2 h}$ was obtained as a yellow powder in $23 \%$ yield: m.p. $200-203^{\circ} \mathrm{C}$ (dec); ${ }^{1} \mathrm{H}-\mathrm{NMR}$ $\left(400 \mathrm{MHz}, \mathrm{CD}_{3} \mathrm{COCD}_{3}\right) \delta 7.86(\mathrm{~s}, 1 \mathrm{H}), 7.72(\mathrm{~d}, J=8.3$ 
$\mathrm{Hz}, 1 \mathrm{H}), 7.47(\mathrm{~d}, J=7.0 \mathrm{~Hz}, 1 \mathrm{H}), 7.28-7.23(\mathrm{~m}, 3 \mathrm{H})$, $7.00(\mathrm{~d}, J=8.4 \mathrm{~Hz}, 1 \mathrm{H}), 6.82(\mathrm{~s}, 1 \mathrm{H}), 6.42(\mathrm{~d}, J=0.7$ $\mathrm{Hz}, 1 \mathrm{H}), 5.26(\mathrm{~s}, 2 \mathrm{H}), 2.40(\mathrm{~s}, 3 \mathrm{H}) ;{ }^{13} \mathrm{C}-\mathrm{NMR}(100 \mathrm{MHz}$, DMSO- $\left.d_{6}\right) \delta 176.3,171.8,164.4,160.8,156.4,148.3$, $147.7,145.5,137.2,136.5,134.5,130.7,130.5,129.2$, $128.9,128.6,122.2,115.9,104.5,98.3,93.1,69.1,19.0$; LC/MS (ESI) $m / z$ Found: $407.40(\mathrm{M}+\mathrm{H})^{+}$; Calcd for $\mathrm{C}_{23} \mathrm{H}_{19} \mathrm{O}_{7}$ : 407.11.

2-(3,4-Dihydroxyphenyl)-7-(3-fluorobenzyloxy)-3, 5-dihydroxy-4H-chromen-4-one (2i)

The desired product $2 \mathbf{i}$ was obtained as a yellow powder in $31 \%$ yield: m.p. $233-235^{\circ} \mathrm{C}$ (dec); ${ }^{1} \mathrm{H}-\mathrm{NMR}$ $\left(500 \mathrm{MHz}, \mathrm{CD}_{3} \mathrm{COCD}_{3}\right) \delta 7.85(\mathrm{~s}, 1 \mathrm{H}), 7.12(\mathrm{~d}, J=7.5$ $\mathrm{Hz}, 1 \mathrm{H}), 7.48(\mathrm{q}, J=8.0 \mathrm{~Hz}, 1 \mathrm{H}), 7.37(\mathrm{~d}, J=8.0 \mathrm{~Hz}$, $1 \mathrm{H}), 7.32(\mathrm{~d}, J=10.0 \mathrm{~Hz}, 1 \mathrm{H}), 7.14(\mathrm{t}, J=9.0 \mathrm{~Hz}, 1 \mathrm{H})$, $7.00(\mathrm{~d}, J=8.5 \mathrm{~Hz}, 1 \mathrm{H}), 6.81(\mathrm{~d}, J=1.5 \mathrm{~Hz}, 1 \mathrm{H}), 6.44$ $(\mathrm{d}, J=2.0 \mathrm{~Hz}, 1 \mathrm{H}), 5.32(\mathrm{~s}, 2 \mathrm{H}) ;{ }^{13} \mathrm{C}-\mathrm{NMR}(100 \mathrm{MHz}$, DMSO- $\left.d_{6}\right) \delta 176.3,164.0,163.8,161.4,160.8,156.3$, $148.3,147.8,145.5,139.5,139.4,136.5,131.2,124.2$, $122.2,120.5,115.9,114.8,104.6,98.4,93.2,69.4 ; \mathrm{LC} /$ MS (ESI) $m / z$ Found: $411.30(\mathrm{M}+\mathrm{H})^{+}$; Calcd for $\mathrm{C}_{22} \mathrm{H}_{16} \mathrm{FO}_{7}$ : 411.09 .

7-(3-Chlorobenzyloxy)-2-(3,4-dihydroxyphenyl)-3, 5 -dihydroxy-4H-chromen-4-one (2j)

The desired product $\mathbf{2 \mathbf { j }}$ was obtained as a yellow powder in $28 \%$ yield: m.p. $266-268^{\circ} \mathrm{C}$ (dec); ${ }^{1} \mathrm{H}-\mathrm{NMR}$ $\left(400 \mathrm{MHz}, \mathrm{DMSO}-d_{6}\right) \delta 7.72(\mathrm{~d}, J=1.9 \mathrm{~Hz}, 1 \mathrm{H}), 7.57$ $(\mathrm{d}, J=1.9 \mathrm{~Hz}, 1 \mathrm{H}), 7.55(\mathrm{~s}, 1 \mathrm{H}), 7.45(\mathrm{~m}, 3 \mathrm{H}), 6.90(\mathrm{~d}$, $J=8.5 \mathrm{~Hz}, 1 \mathrm{H}), 6.81(\mathrm{~d}, J=2.0 \mathrm{~Hz}, 1 \mathrm{H}), 6.50(\mathrm{~d}, J=2.0$ $\mathrm{Hz}, 1 \mathrm{H}), 5.26(\mathrm{~s}, 2 \mathrm{H}) ;{ }^{13} \mathrm{C}-\mathrm{NMR}\left(100 \mathrm{MHz}, \mathrm{CD}_{3} \mathrm{COCD}_{3}\right)$ $\delta 178.7,165.1,161.6,157.4,148.2,147.3,145.6,139.7$, $134.6,130.9,128.7,128.1,126.6,123.4,121.2,115.9$, 115.6, 104.9, 98.7, 98.6, 70.0; LC/MS (ESI) $\mathrm{m} / \mathrm{z}$ Found: $427.10(\mathrm{M}+\mathrm{H})^{+}$; Calcd for $\mathrm{C}_{22} \mathrm{H}_{16} \mathrm{ClO}_{7}$ : 427.06 .

7-(3-Bromobenzyloxy)-2-(3,4-dihydroxyphenyl)-3, 5-dihydroxy-4H-chromen-4-one (2k)

The desired product $\mathbf{2 k}$ was obtained as a yellow powder in $26 \%$ yield: m.p. $200-203^{\circ} \mathrm{C}$ (dec); ${ }^{1} \mathrm{H}-\mathrm{NMR}$ $\left(400 \mathrm{MHz}, \mathrm{CD}_{3} \mathrm{COCD}_{3}\right) \delta 7.86(\mathrm{~d}, J=1.6 \mathrm{~Hz}, 1 \mathrm{H}), 7.73$ $(\mathrm{s}, 1 \mathrm{H}), 7.71(\mathrm{~d}, J=1.8 \mathrm{~Hz}, 1 \mathrm{H}), 7.56-7.53(\mathrm{~m}, 2 \mathrm{H})$, $7.39(\mathrm{t}, J=7.8 \mathrm{~Hz}, 1 \mathrm{H}), 7.01(\mathrm{~d}, J=4.5 \mathrm{~Hz}, 1 \mathrm{H}), 6.80$ $(\mathrm{d}, J=2.1 \mathrm{~Hz}, 1 \mathrm{H}), 6.43(\mathrm{~d}, J=2.0 \mathrm{~Hz}, 1 \mathrm{H}), 5.30(\mathrm{~s}$, $2 \mathrm{H}) ;{ }^{13} \mathrm{C}-\mathrm{NMR}\left(100 \mathrm{MHz}, \mathrm{DMSO}-d_{6}\right) \delta 176.3,171.9$, $164.0,160.8,156.3,148.3,147.8,145.5,139.4,136.5$, $131.5,131.0,127.3,127.0,122.3,120.5,120.2,116.0$, 104.6, 98.3, 93.2, 69.3; LC/MS (ESI) $\mathrm{m} / z$ Found: 471.20 (M+H) ; Calcd for $\mathrm{C}_{22} \mathrm{H}_{16} \mathrm{BrO}_{7}$ : 471.01.

2-(3,4-Dihydroxyphenyl)-3,5-dihydroxy-7-(3-iodobenzyloxy)-4H-chromen-4-one (2l)
The desired product $\mathbf{2 1}$ was obtained as a yellow powder in $14 \%$ yield: m.p. $230-233^{\circ} \mathrm{C}$ (dec); ${ }^{1} \mathrm{H}-\mathrm{NMR}(400 \mathrm{MHz}$, DMSO- $\left.d_{6}\right) \delta 7.86(\mathrm{~s}, 1 \mathrm{H}), 7.73(\mathrm{~d}, J=2.2 \mathrm{~Hz}, 2 \mathrm{H}), 7.57$ (dd, $J=8.5,2.2 \mathrm{~Hz}, 1 \mathrm{H}), 7.52(\mathrm{~d}, J=10.2 \mathrm{~Hz}, 1 \mathrm{H}), 7.23$ $(\mathrm{t}, J=7.8 \mathrm{~Hz}, 1 \mathrm{H}), 6.91(\mathrm{~d}, J=8.5 \mathrm{~Hz}, 1 \mathrm{H}), 6.80(\mathrm{~d}, J$ $=2.2 \mathrm{~Hz}, 1 \mathrm{H}), 6.45(\mathrm{~d}, J=2.2 \mathrm{~Hz}, 1 \mathrm{H}), 5.22(\mathrm{~s}, 2 \mathrm{H}) ;{ }^{13} \mathrm{C}$ NMR $\left(100 \mathrm{MHz}\right.$, DMSO- $\left.d_{6}\right) \delta 176.8,164.4,161.3$, $156.8,148.7,148.2,145.9,139.7,137.6,137.0,136.9$, $131.5,127.9,122.6,120.8,116.4,116.1,105.0,98.8$, 95.7, 93.6, 69.7; LC/MS (ESI) $\mathrm{m} / z$ Found: 519.40 $(\mathrm{M}+\mathrm{H})^{+}$; Calcd for $\mathrm{C}_{22} \mathrm{H}_{16} \mathrm{IO}_{7}: 518.99$.

3-((2-(3,4-Dihydroxyphenyl)-3,5-dihydroxy-4-oxo$4 H$-chromen-7-yloxy)methyl)benzo-nitrile (2m)

The desired product $2 \mathrm{~m}$ was obtained as a yellow powder in $29 \%$ yield: m.p. $236-239^{\circ} \mathrm{C}$ (dec); ${ }^{1} \mathrm{H}-\mathrm{NMR}$ $\left(400 \mathrm{MHz}, \mathrm{DMSO}-d_{6}\right) \delta 7.96(\mathrm{~s}, 1 \mathrm{H}), 7.84(\mathrm{t}, J=8.0$ $\mathrm{Hz}, 2 \mathrm{H}), 7.75(\mathrm{~d}, J=2.0 \mathrm{~Hz}, 1 \mathrm{H}), 7.65(\mathrm{t}, J=7.9 \mathrm{~Hz}$, $1 \mathrm{H}), 7.56(\mathrm{dd}, J=8.4,2.0 \mathrm{~Hz}, 1 \mathrm{H}), 6.90(\mathrm{~d}, J=8.4 \mathrm{~Hz}$, $1 \mathrm{H}), 6.82(\mathrm{~d}, J=2.0 \mathrm{~Hz}, 1 \mathrm{H}), 6.47(\mathrm{~d}, J=2.1 \mathrm{~Hz}, 1 \mathrm{H})$, $5.31(\mathrm{~s}, 2 \mathrm{H}) ;{ }^{13} \mathrm{C}-\mathrm{NMR}\left(100 \mathrm{MHz}, \mathrm{CD}_{3} \mathrm{COCD}_{3}\right) \delta 176.6$, $165.2,157.6,148.3,147.4,145.7,139.3,137.0,132.9$, 132.6, 131.8, 130.7, 123.7, 121.5, 121.4, 119.1, 116.2, 115.8, 113.5, 105.1, 98.9, 93.7, 69.9; LC/MS (ESI) $\mathrm{m} / z$ Found: $418.20(\mathrm{M}+\mathrm{H})^{+}$; Calcd for $\mathrm{C}_{23} \mathrm{H}_{16} \mathrm{NO}_{7}$ : 418.09 .

2-(3,4-Dihydroxyphenyl)-3,5-dihydroxy-7-(3-nitrobenzyloxy)-4H-chromen-4-one (2n)

The desired product $2 \mathbf{n}$ was obtained as a yellow powder in $30 \%$ yield: m.p. $223-225^{\circ} \mathrm{C}$ (dec); ${ }^{1} \mathrm{H}-\mathrm{NMR}$ $\left(500 \mathrm{MHz}, \mathrm{CD}_{3} \mathrm{COCD}_{3}\right) \delta 8.41(\mathrm{~s}, 1 \mathrm{H}), 8.25(\mathrm{~d}, J=7.0$ $\mathrm{Hz}, 1 \mathrm{H}), 8.00(\mathrm{~d}, J=7.5 \mathrm{~Hz}, 1 \mathrm{H}), 7.86(\mathrm{~s}, 1 \mathrm{H}), 7.76(\mathrm{t}$, $J=8.0 \mathrm{~Hz}, 1 \mathrm{H}), 7.72(\mathrm{~d}, J=8.5 \mathrm{~Hz}, 1 \mathrm{H}), 7.00(\mathrm{~d}, J=$ $8.5 \mathrm{~Hz}, 1 \mathrm{H}), 6.86(\mathrm{~s}, 1 \mathrm{H}), 6.48(\mathrm{~s}, 1 \mathrm{H}), 5.48(\mathrm{~s}, 2 \mathrm{H}) ;{ }^{13} \mathrm{C}-$ NMR $\left(100 \mathrm{MHz}\right.$, DMSO- $\left.d_{6}\right) \delta 176.3,171.9,163.8$, 160.9 , 156.3, 148.3, 148.2, 147.8, 145.5, 138.9, 136.5, 134.5, 123.1, 122.8, 122.2, 120.5, 115.9, 104.7, 98.4, 98.3, 93.2, 68.9; LC/MS (ESI) $m / z$ Found: $438.40(\mathrm{M}+\mathrm{H})^{+}$; Calcd for $\mathrm{C}_{22} \mathrm{H}_{16} \mathrm{NO}_{9}$ : 438.08 .

2-(3,4-Dihydroxyphenyl)-3,5-dihydroxy-7-(3-methylbenzyloxy)-4H-chromen-4-one (2o)

The desired product $\mathbf{2 0}$ was obtained as a yellow powder in $22 \%$ yield: m.p. $206-209^{\circ} \mathrm{C}$ (dec); ${ }^{1} \mathrm{H}-\mathrm{NMR}(500$ $\left.\mathrm{MHz}, \mathrm{CD}_{3} \mathrm{COCD}_{3}\right) \delta 7.86(\mathrm{~s}, 1 \mathrm{H}), 7.74(\mathrm{~s}, 1 \mathrm{H}), 7.72(\mathrm{dd}$, $J=8.5,1.5 \mathrm{~Hz}, 1 \mathrm{H}), 7.31(\mathrm{~d}, J=5.0 \mathrm{~Hz}, 2 \mathrm{H}), 7.19(\mathrm{t}, J$ $=3.5 \mathrm{~Hz}, 1 \mathrm{H}), 7.01(\mathrm{~d}, J=8.5 \mathrm{~Hz}, 1 \mathrm{H}), 6.80(\mathrm{~d}, J=2.0$ $\mathrm{Hz}, 1 \mathrm{H}), 6.41(\mathrm{~d}, J=2.0 \mathrm{~Hz}, 1 \mathrm{H}), 5.24(\mathrm{~s}, 2 \mathrm{H}), 2.36(\mathrm{~s}$, $3 \mathrm{H}) ;{ }^{13} \mathrm{C}-\mathrm{NMR}\left(100 \mathrm{MHz}, \mathrm{DMSO}-d_{6}\right) \delta 176.3,164.3$, $160.8,156.4,148.2,147.7,145.5,138.1,136.5,136.4$, $128.9,128.7,125.3,125.2,122.2,120.6,120.2,116.0$, 104.5, 98.3, 93.1, 70.4, 21.5; LC/MS (ESI) $m / z$ Found: $407.40(\mathrm{M}+\mathrm{H})^{+}$; Calcd for $\mathrm{C}_{23} \mathrm{H}_{19} \mathrm{O}_{7}: 407.11$. 
2-(3,4-Dihydroxyphenyl)-3,5-dihydroxy-7-(3-methoxybenzyloxy)-4H-chromen-4-one (2p)

The desired product $\mathbf{2 p}$ was obtained as a yellow powder in $22 \%$ yield: m.p. $214-218^{\circ} \mathrm{C}$ (dec); ${ }^{1} \mathrm{H}-\mathrm{NMR}$ $\left(500 \mathrm{MHz}, \mathrm{CD}_{3} \mathrm{COCD}_{3}\right) \delta 7.86(\mathrm{~s}, 1 \mathrm{H}), 7.72(\mathrm{~d}, J=8.5$ $\mathrm{Hz}, 1 \mathrm{H}), 7.34(\mathrm{t}, J=8.0 \mathrm{~Hz}, 1 \mathrm{H}), 7.09(\mathrm{~d}, J=8.0 \mathrm{~Hz}$, $1 \mathrm{H}), 7.00(\mathrm{~d}, J=8.5 \mathrm{~Hz}, 1 \mathrm{H}), 6.93(\mathrm{~d}, J=8.0 \mathrm{~Hz}, 1 \mathrm{H})$, $6.80(\mathrm{~d}, J=2.0 \mathrm{~Hz}, 1 \mathrm{H}), 6.42(\mathrm{~d}, J=2.0 \mathrm{~Hz}, 1 \mathrm{H}), 5.26$ $(\mathrm{s}, 2 \mathrm{H}), 3.82(\mathrm{~s}, 3 \mathrm{H}) ;{ }^{13} \mathrm{C}-\mathrm{NMR}\left(100 \mathrm{MHz}\right.$, DMSO- $\left.d_{6}\right) \delta$ $176.3,164.2,160.8,159.8,156.3,148.2,147.7,145.5$, $138.1,136.4,130.2,129.9,122.2,120.5,120.3,116.0$, 113.8, 113.6, 104.5, 98.4, 93.2, 70.1, 55.5; LC/MS (ESI) $m / z$ Found: $423.30(\mathrm{M}+\mathrm{H})^{+}$; Calcd for $\mathrm{C}_{23} \mathrm{H}_{19} \mathrm{O}_{7}: 423.11$.

2-(3,4-Dihydroxyphenyl)-7-(4-fluorobenzyloxy)-3, 5-dihydroxy-4H-chromen-4-one (2q)

The desired product $\mathbf{2 q}$ was obtained as a yellow powder in $30 \%$ yield: m.p. $212-215^{\circ} \mathrm{C}$ (dec); ${ }^{1} \mathrm{H}-\mathrm{NMR}$ $\left(500 \mathrm{MHz}, \mathrm{CD}_{3} \mathrm{COCD}_{3}\right) \delta 7.86(\mathrm{~s}, 1 \mathrm{H}), 7,72(\mathrm{~d}, J=8.0$ $\mathrm{Hz}, 1 \mathrm{H}), 7.59(\mathrm{t}, J=8.0 \mathrm{~Hz}, 2 \mathrm{H}), 7.20(\mathrm{t}, J=8.5 \mathrm{~Hz}$, $2 \mathrm{H}), 7.01(\mathrm{~d}, J=8.5 \mathrm{~Hz}, 1 \mathrm{H}), 6.79(\mathrm{~s}, 1 \mathrm{H}), 6.41(\mathrm{~s}, 1 \mathrm{H})$, $5.27(\mathrm{~s}, 2 \mathrm{H}) ;{ }^{13} \mathrm{C}-\mathrm{NMR}\left(100 \mathrm{MHz}, \mathrm{DMSO}-d_{6}\right) \delta 176.4$, $164.2,161.4,160.9,156.5,148.3,147.8,145.6,136.5$, $132.9,130.7,130.6,122.3,120.5,116.0,115.8,104.6$, 98.5, 93.2, 69.7; LC/MS (ESI) $\mathrm{m} / z$ Found: 411.40 $(\mathrm{M}+\mathrm{H})^{+}$; Calcd for $\mathrm{C}_{22} \mathrm{H}_{16} \mathrm{FO}_{7}: 411.09$.

7-(4-Chlorobenzyloxy)-2-(3,4-dihydroxyphenyl)-3, 5-dihydroxy-4H-chromen-4-one (2r)

The desired product $\mathbf{2 r}$ was obtained as a yellow powder in $25 \%$ yield: m.p. $228-230^{\circ} \mathrm{C}$ (dec); ${ }^{1} \mathrm{H}-\mathrm{NMR}$ $\left(400 \mathrm{MHz}, \mathrm{DMSO}-d_{6}\right) \delta 7.72(\mathrm{~d}, J=1.9 \mathrm{~Hz}, 1 \mathrm{H}), 7.56$ $(\mathrm{dd}, J=8.4,1.9 \mathrm{~Hz}, 1 \mathrm{H}), 7.50(\mathrm{~m}, 4 \mathrm{H}), 6.90(\mathrm{~d}, J=8.5$ $\mathrm{Hz}, 1 \mathrm{H}), 6.80(\mathrm{~d}, J=1.8 \mathrm{~Hz}, 1 \mathrm{H}), 6.44(\mathrm{~d}, J=1.9 \mathrm{~Hz}$, $1 \mathrm{H}), 5.25(\mathrm{~s}, 2 \mathrm{H}) ;{ }^{13} \mathrm{C}-\mathrm{NMR}\left(100 \mathrm{MHz}, \mathrm{CD}_{3} \mathrm{COCD}_{3}\right) \delta$ $177.1,165.7,162.1,157.9,148.9,148.0,146.3,136.7$, 134.7, 130.6, 129.8, 123.9, 121.8, 116.4, 116.1, 105.5, 100.6, 99.2, 94.0, 70.0; LC/MS (ESI) $\mathrm{m} / z$ Found: $427.20(\mathrm{M}+\mathrm{H})^{+}$; Calcd for $\mathrm{C}_{22} \mathrm{H}_{16} \mathrm{ClO}_{7}: 427.06$.

7-(4-Bromobenzyloxy)-2-(3,4-dihydroxyphenyl)-3, 5-dihydroxy-4H-chromen-4-one (2s)

The desired product $\mathbf{2} \mathbf{s}$ was obtained as a yellow powder in $22 \%$ yield: m.p. $255-258^{\circ} \mathrm{C}$ (dec); ${ }^{1} \mathrm{H}-\mathrm{NMR}$ (400 $\left.\mathrm{MHz}, \mathrm{CD}_{3} \mathrm{COCD}_{3}\right) \delta 7.85(\mathrm{~s}, 1 \mathrm{H}), 7.71(\mathrm{~d}, J=8.4 \mathrm{~Hz}$, $1 \mathrm{H}), 7.62(\mathrm{~d}, J=8.4 \mathrm{~Hz}, 2 \mathrm{H}), 7.50(\mathrm{~d}, J=8.4 \mathrm{~Hz}, 2 \mathrm{H})$, $7.00(\mathrm{~d}, J=8.5 \mathrm{~Hz}, 1 \mathrm{H}), 6.79(\mathrm{~d}, J=1.4 \mathrm{~Hz}, 1 \mathrm{H}), 6.41$ $(\mathrm{d}, J=1.6 \mathrm{~Hz}, 1 \mathrm{H}), 5.27(\mathrm{~s}, 2 \mathrm{H}) ;{ }^{13} \mathrm{C}-\mathrm{NMR}(100 \mathrm{MHz}$, DMSO- $\left.d_{6}\right) \delta 174.4,162.1,159.0,154.4,146.3,145.8$, $143.6,134.5,134.2,129.9,128.4,12.3,119.7,118.5$, 114.0, 113.7, 102.7, 96.5, 91.3, 67.5; LC/MS (ESI) $\mathrm{m} / z$ Found: $471.30(\mathrm{M}+\mathrm{H})^{+}$; Calcd for $\mathrm{C}_{22} \mathrm{H}_{16} \mathrm{BrO}_{7}: 471.01$.
2-(3,4-Dihydroxyphenyl)-3,5-dihydroxy-7-(4-iodobenzyloxy)-4H-chromen-4-one (2t)

The desired product $\mathbf{2 t}$ was obtained as a yellow powder in $20 \%$ yield: m.p. $259-262^{\circ} \mathrm{C}$ (dec); ${ }^{1} \mathrm{H}-\mathrm{NMR}$ $\left(400 \mathrm{MHz}\right.$, DMSO- $\left.d_{6}\right) \delta 7.79(\mathrm{~d}, J=8.2 \mathrm{~Hz}, 2 \mathrm{H}), 7.73$ $(\mathrm{d}, J=2.0 \mathrm{~Hz}, 1 \mathrm{H}), 7.57(\mathrm{dd}, J=8.5,2.1 \mathrm{~Hz}, 1 \mathrm{H}), 7.29$ $(\mathrm{d}, J=8.2 \mathrm{~Hz}, 2 \mathrm{H}), 6.90(\mathrm{~d}, J=8.5 \mathrm{~Hz}, 1 \mathrm{H}), 6.78(\mathrm{~d}, J=$ $2.1 \mathrm{~Hz}, 1 \mathrm{H}), 5.21(\mathrm{~s}, 2 \mathrm{H}) ;{ }^{13} \mathrm{C}-\mathrm{NMR}(100 \mathrm{MHz}$, DMSO$\left.d_{6}\right) \delta 176.3,164.0,160.8,156.3,148.3,147.7,145.5$, $137.7,136.5,136.4,130.3,122.2,120.4,115.9,115.6$, 104.6, 98.3, 94.6, 93.2, 69.6; LC/MS (ESI) $m / z$ Found: $519.30(\mathrm{M}+\mathrm{H})^{+}$; Calcd for $\mathrm{C}_{22} \mathrm{H}_{16} \mathrm{IO}_{7}: 518.99$.

4-((2-(3,4-Dihydroxyphenyl)-3,5-dihydroxy-4-oxo$4 H$-chromen-7-yloxy)methyl)benzo-nitrile (2u)

The desired product $2 \mathbf{u}$ was obtained as a yellow powder in $29 \%$ yield: m.p. $212-215^{\circ} \mathrm{C}$ (dec); ${ }^{1} \mathrm{H}-\mathrm{NMR}$ $\left(500 \mathrm{MHz}, \mathrm{CD}_{3} \mathrm{COCD}_{3}\right) \delta 7.86(\mathrm{~d}, J=8.0 \mathrm{~Hz}, 3 \mathrm{H}), 7.76$ $(\mathrm{d}, J=8.0 \mathrm{~Hz}, 2 \mathrm{H}), 7.71(\mathrm{~d}, J=8.0 \mathrm{~Hz}, 1 \mathrm{H}), 7.01(\mathrm{~d}, J$ $=8.5 \mathrm{~Hz}, 1 \mathrm{H}), 6.82(\mathrm{~s}, 1 \mathrm{H}), 6.45(\mathrm{~d}, J=1.5 \mathrm{~Hz}, 1 \mathrm{H})$, $5.43(\mathrm{~s}, 2 \mathrm{H}) ;{ }^{13} \mathrm{C}-\mathrm{NMR}\left(125 \mathrm{MHz}, \mathrm{CD}_{3} \mathrm{COCD}_{3}\right) \delta 176.4$, $163.9,161.0,156.4,148.4,147.9,145.6,142.5,136.6$, $133.0,128.6,122.3,120.5,119.2,116.0,115.8,111.2$, 104.8, 98.5, 93.3, 69.4; LC/MS (ESI) $\mathrm{m} / z$ Found: $418.30(\mathrm{M}+\mathrm{H})^{+}$; Calcd for $\mathrm{C}_{23} \mathrm{H}_{16} \mathrm{NO}_{7}: 418.09$.

2-(3,4-Dihydroxyphenyl)-3,5-dihydroxy-7-(4-nitrobenzyloxy)-4H-chromen-4-one (2v)

The desired product $\mathbf{2 v}$ was obtained as a yellow powder in $24 \%$ yield: m.p. $225-227^{\circ} \mathrm{C}$ (dec); ${ }^{1} \mathrm{H}-\mathrm{NMR}$ $\left(500 \mathrm{MHz}, \mathrm{CD}_{3} \mathrm{COCD}_{3}\right) \delta 8.31(\mathrm{~d}, J=8.5 \mathrm{~Hz}, 2 \mathrm{H}), 7.83$ $(\mathrm{d}, J=8.5 \mathrm{~Hz}, 3 \mathrm{H}), 7.71(\mathrm{~d}, J=8.5 \mathrm{~Hz}, 1 \mathrm{H}), 7.00(\mathrm{~d}, J$ $=8.5 \mathrm{~Hz}, 1 \mathrm{H}), 6.83(\mathrm{~s}, 1 \mathrm{H}), 6.46(\mathrm{~s}, 1 \mathrm{H}), 5.48(\mathrm{~s}, 2 \mathrm{H})$; ${ }^{13} \mathrm{C}-\mathrm{NMR}\left(100 \mathrm{MHz}, \mathrm{DMSO}-d_{6}\right) \delta 174.5,161.9,159.0$, $154.5,146.5,146.0,145.7,143.6,142.6,134.6,126.8$, $122.2,120.3,118.5,114.1,113.8,102.9,96.1,91.4$, 67.1; LC/MS (ESI) $m / z$ Found: $438.40(\mathrm{M}+\mathrm{H})^{+}$; Calcd for $\mathrm{C}_{22} \mathrm{H}_{16} \mathrm{NO}_{9}$ : 438.08 .

2-(3,4-Dihydroxyphenyl)-3,5-dihydroxy-7-(4-methylbenzyloxy)- $4 H$-chromen-4-one ( $2 \mathrm{w})$

The desired product $2 \mathbf{w}$ was obtained as a yellow powder in $21 \%$ yield: m.p. $262-264^{\circ} \mathrm{C}$ (dec); ${ }^{1} \mathrm{H}-\mathrm{NMR}$ $\left(500 \mathrm{MHz}, \mathrm{CD}_{3} \mathrm{COCD}_{3}\right) \delta 7.86(\mathrm{~d}, J=2.0 \mathrm{~Hz}, 1 \mathrm{H}), 7.72$ (dd, $J=8.5,2.5 \mathrm{~Hz}, 1 \mathrm{H}), 7.41(\mathrm{~d}, J=7.5 \mathrm{~Hz}, 2 \mathrm{H}), 7.24$ $(\mathrm{d}, J=7.5 \mathrm{~Hz}, 2 \mathrm{H}), 7.01(\mathrm{~d}, J=8.5 \mathrm{~Hz}, 1 \mathrm{H}), 6.79(\mathrm{~d}, J$ $=2.0 \mathrm{~Hz}, 1 \mathrm{H}), 6.41(\mathrm{~d}, J=2.0 \mathrm{~Hz}, 1 \mathrm{H}), 5.23(\mathrm{~s}, 2 \mathrm{H})$, $2.35(\mathrm{~s}, 3 \mathrm{H}) ;{ }^{13} \mathrm{C}-\mathrm{NMR}\left(100 \mathrm{MHz}, \mathrm{DMSO}-d_{6}\right) \delta 175.8$, $163.8,160.3,155.9,147.8,147.2,145.0,137.3,135.9$, $1331,129.0,127.8,121.7,119.9,115.5,115.2,104.0$, 97.9, 92.7, 69.8, 20.7; LC/MS (ESI) $m / z$ Found: 423.30 $(\mathrm{M}+\mathrm{H})^{+}$; Calcd for $\mathrm{C}_{23} \mathrm{H}_{19} \mathrm{O}_{8}$ : 423.11 . 
2-(3,4-Dihydroxyphenyl)-3,5-dihydroxy-7-(4-methoxybenzyloxy)- $4 H$-chromen-4-one (2x)

The desired product $\mathbf{2 x}$ was obtained as a yellow powder in $19 \%$ yield: m.p. $217-219^{\circ} \mathrm{C}$ (dec); ${ }^{1} \mathrm{H}-\mathrm{NMR}$ $\left(500 \mathrm{MHz}, \mathrm{CD}_{3} \mathrm{COCD}_{3}\right) \delta 7.86(\mathrm{~s}, 1 \mathrm{H}), 7.72(\mathrm{~d}, J=8.0$ $\mathrm{Hz}, 1 \mathrm{H}), 7.45(\mathrm{~d}, J=8.5 \mathrm{~Hz}, 2 \mathrm{H}), 7.01-6.95(\mathrm{~m}, 3 \mathrm{H})$, $6.78(\mathrm{~d}, J=2.0 \mathrm{~Hz}, 1 \mathrm{H}), 6.39(\mathrm{~d}, J=1.5 \mathrm{~Hz}, 1 \mathrm{H}), 5.19$ $(\mathrm{s}, 2 \mathrm{H}), 3.82(\mathrm{~s}, 3 \mathrm{H}) ;{ }^{13} \mathrm{C}-\mathrm{NMR}\left(100 \mathrm{MHz}\right.$, DMSO- $\left.d_{6}\right) \delta$ $176.3,164.3,160.7,156.4,156.3,147.7,145.4,136.4$, $130.9,129.3,128.4,122.3,122.2$, 121.2, 116.7, 115.1, 113.5, 110.0, 104.4, 56.2, 54.8; LC/MS (ESI) $\mathrm{m} / z$ Found: $407.30(\mathrm{M}+\mathrm{H})^{+}$; Calcd for $\mathrm{C}_{23} \mathrm{H}_{19} \mathrm{O}_{7}$ : 407.11.

\section{Anti-SCV assay}

Carboxytetramethylrhodamine (TAMRA)-modified 45-base-oligomer and fluorescein-modified 25-baseoligomer were purchased from Integrated DNA Technologies: 5'-20T25Tam (5'-TTTTTTTTTTTTTTTTTTTTGAGCGGATTACTATACTACATTAGA (TAMRA)3') and 3'-0T25Flu (5'-(Fluorescein) TCTAATGTAGTATAGTAATCCGCTC-3'). The helicase substrate was prepared by annealing the two oligomers, which resulted in 25 base pairs of dsDNA with single-stranded $20 \mathrm{dT}$ of 5'-overhang. A $80 \mu \mathrm{L}$ solution of SCV helicase (150 $\mathrm{nM}$ ) in $20 \mathrm{mM}$ HEPES (pH 7.4) buffer was added to each well of the 96-well assay plate which already contained $1 \mu \mathrm{L}$ of various concentrations of chemical compounds. After 5 min incubation at rt, the FRET based dsDNA unwinding assay was started by addition of $20 \mu \mathrm{L} 5 \mathrm{X}$ reaction solution $\left[5 \mathrm{mM} \mathrm{MgCl}_{2}, 45\right.$ mM ATP, $25 \mathrm{mM}$ DTT, and $100 \mathrm{nM}$ dsDNA substrate in $20 \mathrm{mM}$ HEPES ( $\mathrm{pH} 7.4)]$. The reaction mixture was further incubated for $2 \mathrm{~min}$ at $37^{\circ} \mathrm{C}$ and stopped with $100 \mu \mathrm{L}$ of termination solution [0.1 M EDTA and 0.4 $\mu \mathrm{M}$ trap DNA (unmodified 25 bases 3'-0T25 oligomer) in $20 \mathrm{mM}$ HEPES (pH 7.4)]. The sample was excited at $485 \mathrm{~nm}$ and the fluorescence was measured at 535 $\mathrm{nm}$.

\section{Anti-HCV assay}

The human hepatoma cell line Huh-7, carrying the subgenomic HCV genotype 1 replicon with the luc-ubineo (reporter/selective) fusion gene, was kindly provided by Dr. Ralf Bartenschlager (University of Heidelberg). Huh-5-2 cells were seeded at a density of $5 \times 10^{3}$ per well in a tissue culture-treated white 96-well view plate in complete DMEM supplemented with $500 \mu \mathrm{g} /$ $\mathrm{mL}$ G418. After incubation for $24 \mathrm{~h}$ at $37^{\circ} \mathrm{C}\left(5 \% \mathrm{CO}_{2}\right)$, medium was refreshed (with G418) and DMSO stock of test compounds were added. After 4 days of incubation at $37^{\circ} \mathrm{C}$, cell culture medium was removed and luciferase activity was determined using the SteadyGlo luciferase assay system (Promega).

\section{Cytostatic effect}

Huh-5-2 cells were seeded at a density of $5 \times 10^{3}$ per well of 96-well plate in complete DMEM with the appropriate concentrations of G418. Serial dilutions of the test compounds in complete DMEM without G418 were added $24 \mathrm{~h}$ after seeding. Cells were allowed to proliferate for 3 days at $37^{\circ} \mathrm{C}$, after which the cell number was determined by WST-1 assay.

\section{RESULTS AND DISCUSSION}

\section{Chemistry}

Regioselective alkylation of quercetin requires selective protection of the five phenolic hydroxyl groups. For preparation of the 7-O-alkylated quercetin derivatives, we adapted a general synthetic protocol which includes peracetylation followed by regioselective deacetylation (Scheme 1).

Thus, acetylation of quercetin (1) with acetic anhydride $\left(\mathrm{Ac}_{2} \mathrm{O}\right)$ in pyridine afforded the peracetylated quercetin derivative 4 , which underwent regioselective deacethylation with $\mathrm{PhSH}$ in $\mathrm{NMP}$ ( $\mathrm{Li}$ et al., 2003; Sabui and Venkateswaran, 2003; Lee C et al., 2009a; Lee HS et al., 2010) to provide the corresponding quercetin 3,5,3',4'-tetraacetates 5 in $74 \%$ yield. Alkylation of $\mathbf{5}$ with variously substituted benzyl bromides followed by deacetylation by treatment with methanolic ammonia afforded a series of 7-O-arylmethylquercetins $\mathbf{2} \mathbf{a} \sim \mathbf{2} \mathbf{x}$ in moderate yields.

\section{Biological activity}

All synthesized quercetin arylmethyl ethers $(\mathbf{2} \mathbf{a} \sim \mathbf{2 x})$ were evaluated for their inhibitory activity against both NTPase and helicase activity of the SCV NTPase /helicase (Lee C et al., 2009a, 2009b; Lee HS et al., 2010), which was summarized in Table $\mathrm{I}$ as $\mathrm{IC}_{50}$ values. The anti-HCV activity of the 7-O-arylmethylquercetin derivatives in the human hepatoma cell line Huh-7, carrying the subgenomic HCV genotype 1 replicon with the luc-ubi-neo fusion gene (Lohmann et al., 1999; Vroljk et al., 2003) was also evaluated. INF- $\alpha$ was included as a positive control, and the conditions of the luminescence-based assay used to test the antiviral activity of the compounds were previously described (Gozdek et al., 2008). The cytostatic effect of the test compounds was evaluated in the same cell line. Anti-HCV effect and cytostatic effect are summarized as $\mathrm{EC}_{50}$ and $\mathrm{CC}_{50}$, respectively, in Table I. Assays were performed in triplicate and the data in Table I are the mean of three experiments.

Other than the previously reported 7-O-arylmethylquercetins such as $\mathbf{2 j}, \mathbf{2 m}$, and $\mathbf{2 r}$ (Lee et al., 2009a) with 3 "-Cl, 3"-CN, and 4"-Cl substituent, respectively, 


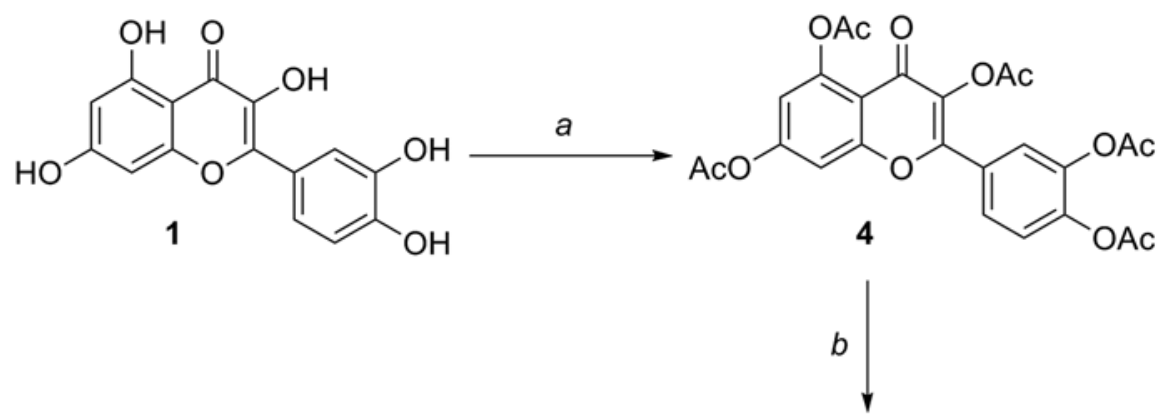

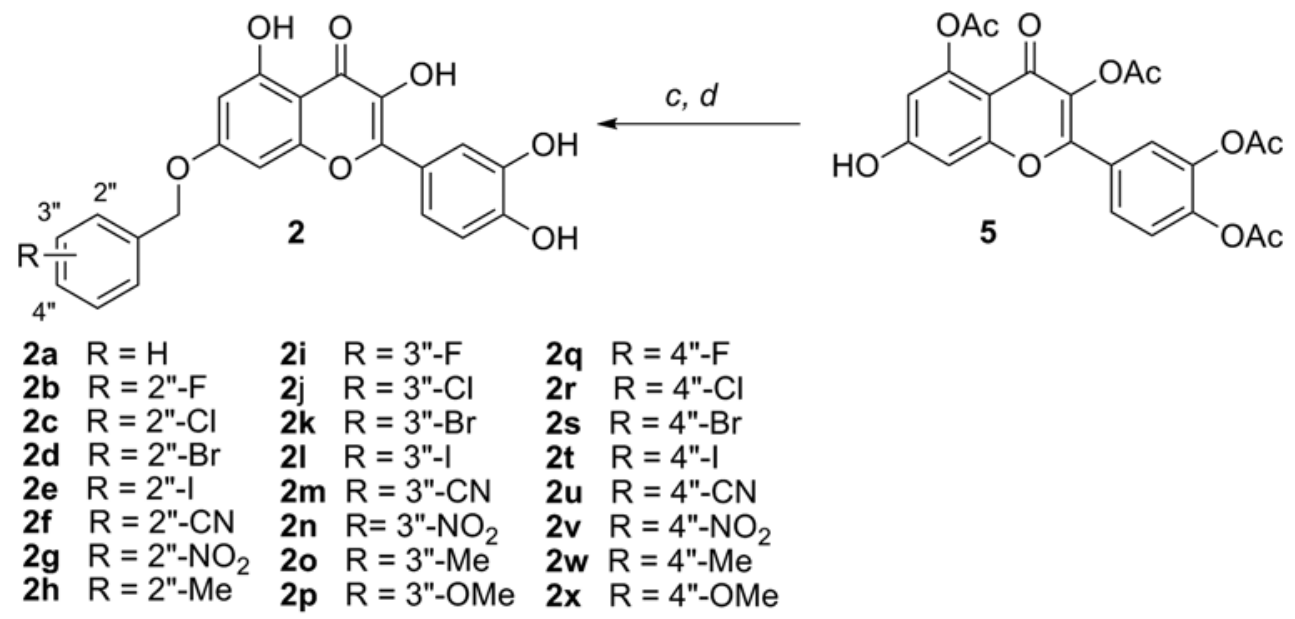

Reagents and conditions: (a) $\mathrm{Ac}_{2} \mathrm{O}$, pyridine, $80^{\circ} \mathrm{C}$; (b) $\mathrm{PhSH}, \mathrm{NMP}$, imidazole, $0^{\circ} \mathrm{C}$; (c) $\mathrm{K}_{2} \mathrm{CO}_{3}, \mathrm{RBnBr}$, acetone; (d) $\mathrm{NH}_{3}, \mathrm{MeOH}, 0^{\circ} \mathrm{C}$

Scheme 1. Synthesis of the 7-O-arylmethylquercetin derivatives (2a $2 \mathbf{2})$ from quercetin (1)

no compound tested in this study showed inhibitory activity against SCV NTPase/helicase. Thus, it is conceivable that binding sites specific for aromatic substituents might be present in the viral target enzyme. More specifically, the NTPase favors 3"-CN and 4"-Cl whereas the helicase has no specific preference among the three substituents.

On the other hand, anti-HCV activity of the quercetin derivatives was evaluated by the HCV replicon cellbased assay. As this assay is based on the luciferase activity co-expressed with the viral proteins inside the Huh-7 cell line harboring the HCV replicon, estimation of the cytotoxicity of the test compounds is an important aspect of understanding the compounds' antiviral activity. Therefore, the cell-based antiviral assay was conducted in parallel with the cytotoxicity assay. All the quercetin derivatives synthesized in this study showed moderate anti-HCV activity in the HCV replicon cell-based assay $\left(\mathrm{EC}_{50}=5 \sim 34 \mu \mathrm{M}\right.$, Table I). However, the 7-O-arylmethylquercetin derivatives were generally toxic against the Huh-7 cell line harboring the HCV replicon with $\mathrm{CC}_{50}$ values of 10 20 $\mu \mathrm{M}$ (Table I) and thus, the substituent-independent anti-HCV activity seems like to be originated from the cytotoxic effect of the quercetin derivatives. Considering the well known anticancer mechanisms of quercetin (Ferry et al., 1996; Lamson and Brignall, 2000), the cytotoxic effect of the quercetin derivatives is not surprising but some of them showed no cytotoxicity up to $100 \mu \mathrm{M}$ (Table I). Thus, only those five 7-O-arylmethylquercetins (2a, $\mathbf{2 g}, \mathbf{2 v} \sim \mathbf{2 x})$ showed selective anti-HCV activity with $\mathrm{EC}_{50}$ values of $25.7,11.1,8.9,23.5$, and $33.9 \mu \mathrm{M}$, respectively. Interestingly, the derivatives with a strongly electron-withdrawing nitro substituent at the ortho $\left(2 \mathrm{~g}, \mathrm{R}=2-\mathrm{NO}_{2}\right)$ and para $\left(2 \mathbf{v}, \mathrm{R}=4-\mathrm{NO}_{2}\right)$ position of the aromatic ring showed the most potent anti-HCV activity (11.1 and $8.9 \mu \mathrm{M}$, respectively) with no cytotoxicity, which suggests a possible role of the electronic property around the aromatic ring for bioactivity.

In conclusion, in this study, we prepared 24 derivatives of 7-O-arylmethylquercetins and evaluated their antiviral activity against SCV as well as HCV. Among those, three derivatives with $3 "-\mathrm{Cl}, 3 "-\mathrm{CN}$, and $4 "-\mathrm{Cl}$ aromatic substituents showed selective inhibitory activity against SCV NTPase/helicase. On the other hand, due to the cytotoxicity associated with the test 
Table I. Anti-HCV activity and inhibition of the SCV NTPase/helicase of the 7-O-arylmethylquercetins (2a $2 \mathbf{2 x})$

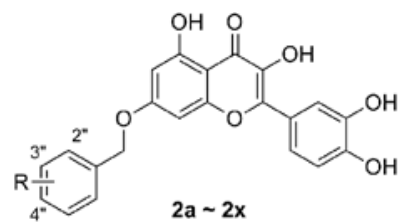

\begin{tabular}{|c|c|c|c|c|c|}
\hline \multirow{2}{*}{ Compds } & \multirow{2}{*}{$\mathrm{R}$} & \multicolumn{2}{|c|}{ Anti-SCV $\left(\mathrm{IC}_{50}, \mu \mathrm{M}\right)$} & \multicolumn{2}{|c|}{ Anti-HCV } \\
\hline & & NTPase $^{\mathrm{c}}$ & Helicase $^{\mathrm{d}}$ & $\mathrm{EC}_{50}, \mu \mathrm{M}^{2}$ & $\mathrm{CC}_{50}, \mu \mathrm{M}^{\mathrm{b}}$ \\
\hline $\mathbf{2 a}$ & $\mathrm{H}$ & $>50$ & $>50$ & 25.7 & $>100$ \\
\hline $2 b$ & $2 "-F$ & $>50$ & $>50$ & 10.0 & 22.5 \\
\hline $2 c$ & $2 "-\mathrm{Cl}$ & $>50$ & $>50$ & 9.0 & 16.5 \\
\hline $2 d$ & $2 "-B r$ & $>50$ & $>50$ & 11.8 & 16.4 \\
\hline $2 e$ & 2"-I & $>50$ & $>50$ & 10.5 & 16.6 \\
\hline $2 f$ & $2 "-\mathrm{CN}$ & $>50$ & $>50$ & 18.0 & 16.5 \\
\hline $2 \mathrm{~g}$ & $2 "-\mathrm{NO}_{2}$ & $>50$ & $>50$ & 11.1 & $>100$ \\
\hline $2 \mathrm{~h}$ & 2"-Me & $>50$ & $>50$ & 11.1 & 21.3 \\
\hline $2 \mathrm{i}$ & $3 "-F$ & $>50$ & $>50$ & 16.8 & 18.9 \\
\hline $2 \mathrm{j}$ & 3"-Cl & $>50^{\mathrm{d}}$ & $5.2^{\mathrm{d}}$ & 25.7 & 17.8 \\
\hline $2 k$ & 3"-Br & $>50$ & $>50$ & 11.3 & 16.8 \\
\hline 21 & 3"-I & $>50$ & $>50$ & 8.2 & 20.0 \\
\hline $2 \mathrm{~m}$ & 3"-CN & $25.4^{\mathrm{e}}$ & $2.7^{\mathrm{d}}$ & 19.3 & 21.1 \\
\hline $2 n$ & 3"- $\mathrm{NO}_{2}$ & $>50$ & $>50$ & 5.1 & 16.7 \\
\hline 20 & 3"-Me & $>50$ & $>50$ & 10.1 & 13.2 \\
\hline $2 p$ & 3"-OMe & $>50$ & $>50$ & 16.7 & 22.4 \\
\hline $2 q$ & 4"-F & $>50$ & $>50$ & 7.7 & 17.5 \\
\hline $2 \mathbf{r}$ & 4"-Cl & $20.9^{\mathrm{d}}$ & $4.1^{\mathrm{d}}$ & 10.1 & 18.2 \\
\hline $2 \mathrm{~s}$ & 4"-Br & $>50$ & $>50$ & 6.8 & 18.6 \\
\hline $2 t$ & $4 "-\mathrm{I}$ & $>50$ & $>50$ & 6.4 & 18.9 \\
\hline $2 \mathbf{u}$ & 4"-CN & $>50$ & $>50$ & 6.3 & 7.0 \\
\hline $2 \mathrm{v}$ & $4 "-\mathrm{NO}_{2}$ & $>50$ & $>50$ & 8.9 & $>100$ \\
\hline $2 w$ & 4"-Me & $>50$ & $>50$ & 23.5 & $>100$ \\
\hline $2 x$ & 4"-OMe & $>50$ & $>50$ & 33.9 & $>100$ \\
\hline
\end{tabular}

${ }^{\mathrm{a}}$ Concentration required to inhibit HCV RNA replication by $50 \%$ in HCV replicon cell. Interferon $\alpha-2 b$ was used as a reference compound at 10000 units/well and reduced the signal to background levels without any cytotoxic activity; ${ }^{\mathrm{b}}$ Concentration required to reduce cell growth by $50 \%$ in $\mathrm{HCV}$ replicon cell; ${ }^{\mathrm{c}}$ Concentration required to inhibit SCV NTPase activity by $50 \%$; ${ }^{\mathrm{d}}$ Concentration required to inhibit duplex DNA-unwinding activity of SCV helicase by 50\%; ' Lee et al., 2009a

compounds, only five quercetin derivatives showed selective antiviral activity in HCV replicon cell-based assay. Taken together, it should be noted that the antiviral effect as well as cytotoxicity of the title compounds could be fine-tuned via selection of the aromatic substituent.

\section{ACKNOWLEDGEMENTS}

This research was supported by a grant of the Korea
Healthcare technology R\&D Project, Ministry for Health, Welfare \& Family Affairs, Republic of Korea (A08-4628-AA2023-08N1-00010A), by Basic Science Research Program through the National Research Foundation of Korea (NRF) funded by the Ministry of Education, Science and Technology (2010-0008260), Priority Research Centers Program through the National Research Foundation of Korea (NRF) funded by the Ministry of Education, Science and Technology (2009-0093824), by a grant from ORP 8-21-52 (NIAS), and by a grant from 2nd Biogreen 21 program PJ007982 (Korea Rural Development Administration).

\section{REFERENCES}

Amoros, M., Simös, C. M. O., Girre, L., Sauvager, F., and Cormier, M., Synergistic effect of flavones and flavonols against herpes simplex virus type 1 in cell culture. Comparison with the antiviral activity of propolis. J. Nat. Prod., 55, 1732-1740 (1992).

Ferry, D. R., Smith, A., Malkhandi, J., Fyfe, D. W., de Takats, P. G., Anderson, D., Baker, J., and Kerr, D. J., Phase I clinical trial of the flavonoid quercetin: pharmacokinetics and evidence for in vivo tyrosine kinase inhibition. Clin. Cancer Res., 2, 659-668 (1996).

Gozdek, A., Zhukov, I., Polkowska, A., Poznanski, J., StankiewiczDrogon, A., Pawlowicz, J. M., Zagorski-Ostoja, W., Borowski, P., and Boguszewska-Chachulska, A., NS3 Peptide, a novel potent hepatitis C virus NS3 helicase inhibitor: Its mechanism of action and antiviral activity in the replicon system. Antimicrob. Agents Chemother., 52, 393-401 (2008).

Harada, S., Haneda, E., Maekawa, T., Morikawa, Y., Funayama, S., Nagata, N., and Ohtsuki, K., Casein kinase II (CK-II)mediated stimulation of HIV-1 reverse transcriptase activity and characterization of selective inhibitors in vitro. Biol. Pharm. Bull., 22, 1122-1126 (1999).

Kaul, T. N., Middleton, E., Jr., and Ogra, P. L., Antiviral effect of flavonoids on human viruses. J. Med. Virol., 15, 71-79 (1985).

Kim, J., Kim, K.-S., Lee, H. S., Park, K.-S., Park, S. Y., Kang, S.-Y., Lee, S. J., Park, H. S., Kim, D.-E., and Chong, Y., Effects of the aryl linker and the aromatic substituent on the anti-HCV activities of aryl diketoacid (ADK) analogues. Bioorg. Med. Chem. Lett., 18, 4661-4665 (2008).

Lamson, D. W. and Brignall, M. S., Antioxidant and cancer III: quercetin. Altern. Med. Rev., 5, 196-208 (2000).

Lee, C., Lee, J. M., Lee, N.-R., Kim, D.-E., Jeong, Y.-J., and Chong, Y., Investigation of the pharmacophore space of severe acute respiratory syndrome coronavirus (SARS$\mathrm{CoV})$ NTPase/helicase by dihydroxychromone derivatives. Bioorg. Med. Chem. Lett., 19, 4538-4541 (2009a).

Lee, C., Lee, J. M., Lee, N.-R., Jin, B.-S., Jang, K. J., Kim, D.E., Jeong, Y.-J., and Chong, Y., Aryl diketoacids (ADK) selectively inhibit duplex DNA-unwinding activity of SARS coronavirus NTPase/helicase. Bioorg. Med. Chem. 
Lett., 19, 1636-1638 (2009b).

Lee, H. S., Park, K.-S., Lee, C., Lee, B., Kim, D.-E., and Chong, Y., 7-O-Arylmethylgalangin as a novel scaffold for anti-HCV agents. Bioorg. Med. Chem. Lett., 20, 5709-5712 (2010).

Li, M., Han, X., and Yu, B., Facile synthesis of flavonoid 7-Oglycosides. J. Org. Chem., 68, 6842-6845 (2003).

Lohmann, V., Korner, F., Koch, J., Herian, U., Theilmann, L., and Bartenschlager, R., Replication of subgenomic hepatitis $\mathrm{C}$ virus RNAs in a hepatoma cell line. Science, 285, 110-113 (1999).
Sabui, S. K. and Venkateswaran, R. V., Synthesis of O-methyl epi-heliannuol E. Tetrahedron, 59, 8375-8381 (2003).

Vrijsen, R., Everaert, L., and Boeyé, A., Antiviral activity of flavones and potentiation by ascorbate. J. Gen. Virol., 69, 1749-1751 (1988).

Vroljk, J. M., Kaul, A., Hansen, B. E., Lohmann, V., Haagmans, B. L., Schalm, S. W., and Bartenschlager, R., A repliconbased bioassay for the measurement of interferons in patients with chronic hepatitis C. J. Virol. Methods, 110, 201-209 (2003). 